\title{
Los 'señores de la tierra' y los mecanismos del abasto de carne en Tlaxcala en el siglo XVI
}

\author{
María Xóchitl Galindo VillaVicencio ${ }^{1}$ \\ Universidad Nacional Autónoma de México (México) \\ xochitl@correo.iia.unam.mx
}

Recepción: 3 de mayo de 2013 / Revisión: 22 de junio de 2013

Aceptación: 2 de agosto de 2013 / Publicación: diciembre de 2014

\section{RESUMEN}

En la década de 1570, se puso en marcha en la provincia de Tlaxcala, la ordenanza del virrey Martín Enríquez que prohibía la venta de carne en pueblos de indios. Dicha prohibición buscaba asegurar el abasto de carne para la república de españoles en una época en la que se vislumbraba escasez de ganado bovino. Sin embargo, este veto tuvo diversos ángulos. En Tlaxcala tomará la forma no de una prohibición, sino de un estanco de carnicerías cuyo control fue retirado de manos del cabildo indio. Lo anterior constituía una revocación de la ordenanza en claro beneficio de los comerciantes de carne españoles, pero en contra de lo que podría pensarse, el cabildo de naturales insistirá en restablecer la prohibición. Para esa misma década, todavía se libraba entre el cabildo y los ganaderos españoles, una seria disputa por la intrusión del ganado en los terrenos de cultivo de los tlaxcaltecas. En este contexto, la prohibición servirá a la élite gobernante de Tlaxcala como trinchera para mantener alejado al ganado, que había afectado a los labradores indios desde hacía por lo menos dos décadas.

Palabras clave: Tlaxcala, indios, abasto de carne, prohibición, ganado bovino, siglo XVI, México.

\section{The 'Landlords' and the operation of meat supply in Tlaxcala in the $16^{\text {th }}$ century}

\begin{abstract}
In the 1570s, in the province of Tlaxcala, Viceroy Martin Enriquez implemented an ordinance which banned the sale of meat in Indian villages. The prohibition intended to secure the meat supply for the Republic of the Spaniards at a time of cattle shortage. But the prohibition had different angles. In Tlaxcala the ordinance took the form of a state meat monopoly that was wrested from indigenous control, rather than a prohibition. This constituted a revocation of the ordinance, clearly benefiting Spanish meat merchants. However, the Indian Council insisted on restoring the ban.

In the same decade, a serious struggle still existed between the Tlaxcalan Indian farmers and the cattle ranchers, over the animals' intrusions to farmlands. In this context, the prohibition would serve the Tlaxcalan ruling elite as a barrier to keep cowherds off the farmlands, a problem that had affected the Indian farmers for at least two decades.
\end{abstract}

Keywords: Tlaxcala, Indians, Meat Supply, Prohibition, Bovine Cattle, $16^{\text {th }}$ century, Mexico.

\footnotetext{
1 Becaria posdoctoral de la Universidad Nacional Autónoma de México (UNAM), Instituto de Investigaciones Antropológicas.
} 
Sumario: 1. Antecedentes. El abasto y la obligación. 2. La prohibición de venta de carne de 1568 y el abasto en Tlaxcala en el siglo XVI. 3. 'Señores de la tierra', 'señores del ganado' y la disputa por la tierra. 4. Conclusiones. 5. Referencias bibliográficas.

\section{ANTECEDENTES. EL ABASTO Y LA OBLIGACIÓN}

Sabemos con certeza que en el siglo XVI en Nueva España, el abasto en las carnicerías de carne de res, cerdo y carnero, estuvo regulado por los cabildos locales. En favor del continuo abastecimiento del mercado de carne, pero también en consideración al mantenimiento de precios y pesos, en general, no se le permitió a ninguna persona sacrificar ganado y vender su carne sin haber obtenido una licencia otorgada por el Virrey, en los casos como el que analizaremos aquí; o bien, a través de una subasta pública en la que el puesto de 'obligado de la carne' era adjudicado al comerciante que ofreciera los mejores precios de venta.

Las penas por el sacrificio y venta ilegal iban desde multas en oro y destierros si algún estanciero o criado de algún 'señor de ganado' sin permiso expreso, mataba y vendía carne de vaca o carnero ${ }^{2}$. Por su parte, los 'obligados', como veremos, únicos abastecedores y beneficiarios del monopolio de la venta de la carne y sus criados, no podían hacer rodeos ${ }^{3}$, actividad reservada para los criadores y dueños de estancias ${ }^{4}$.

La regulación de la venta de carne en Nueva España es más antigua que la introducción de la institución del virreinato mismo, que tuvo lugar en 1535. Algo tan prioritario como el abasto y regulación de este producto, aparece en sesiones de actas de Cabildo de la ciudad de México desde $1524^{5}$, reunido el Ayuntamiento en la villa de Coyoacán y previamente al establecimiento de la Audiencia en 1527. De la ciudad de México es de donde tenemos más información del funcionamiento del abasto de la carne para el siglo $\mathrm{XVI}^{6}$. Pero cabe suponer que en las generalidades y para un período temprano, los mecanismos del abastecimiento fueran similares en el resto de poblaciones del territorio central del Virreinato donde se establecieron carnicerías. Con particularidades que se verán en adelante en el caso de Tlaxcala por tratarse de una república de indios, hemos pensado que una introducción sobre el funcionamiento del abasto en la capital, ayudaría a despejar algunas dudas.

2 Ventura Beleña, 1991, p. 12. Ordenanza del 7-XI-1578.

3 El rodeo es tanto el corral circular, como la actividad de numerosos hombres a caballo de dirigir dentro de éste al ganado. Comúnmente se trataba de ganado cimarrón que se agrupaba con la finalidad de castrarlo, marcarlo, repartir los 'orejanos' o sin marca y sin dueño, o bien, para curarlos y separar aquellos que se mantendrían para el consumo. En el caso de los caballos, para cortarles las crines. Con las Ordenanzas de la Mesta de 1574 los rodeos se hicieron obligatorios. Esta faena, en gran medida se realizaba para agrupar al ganado en hatos y rebaños, acostumbrándolo a la presencia del hombre y estimulando la "querencia" que se encontraba cerca de las estancias donde se realizaban. Tudela DE LA ORdEN, 1993, p. 172.

4 Ventura Beleña, 1991, p. 13. Ordenanza del 18-XI-1578.

5 Acta del 29-III-1524. Actas de Cabildo de la Ciudad de México (en adelante ACCM), libro I, p. 6. El cabildo recibe la oferta de Hernando Alonso que mejoraba la postura vigente de Pedro de Maya para el arrelde (equivalente a cuatro libras) de carne de cerdo. Durante esta década se verá que la carne de cerdo se incluye en la obligación, más adelante, esta carne y sus derivados será parte del gremio de los tocineros. QuiROZ, 2003, p. 192.

6 Dussenberry, 1948; Matesanz, 1965. 
La preocupación del gobierno colonial por asegurar el abastecimiento de la carne, llevó a recurrir al sistema conocido como de 'obligados', un antiguo mecanismo de abasto utilizado en casi todas las ciudades medievales castellanas y fruto del proteccionismo en materia alimentaria. La protección de los precios y medidas en beneficio de los consumidores, la garantía de higiene, pero sobre todo, la posibilidad de abastecer los productos en épocas de carestía, condiciones climáticas adversas, guerras o sequías, fueron las principales preocupaciones que se buscaron mantener bajo control mediante el sistema de la obligación ${ }^{7}$. Las más estrictas regulaciones a este respecto, fueron hechas en relación al mantenimiento de los precios y a que los pesos de la carne estuviesen bien medidos.

En el caso del abasto de carne en la primera mitad del siglo XVI en Nueva España, las disputas no surgirán con relación a ninguno de los posibles escenarios adversos que el sistema preveía, por el contrario, la sobrepoblación de ganado vacuno generó problemas distintos. No será hasta las últimas tres décadas de ese siglo, que veremos una disminución en las cabañas. Esta desaceleración en la reproducción de las vacadas, no traerá como consecuencia el desabasto de productos cárnicos en todo el siglo XVI. Sin embargo, ante la paulatina reducción del ganado, veremos que se pondrán en marcha otras medidas de contención.

La manera de convertirse en empresario de la carne a través del sistema de la obligación, era ganar la subasta que para ello convocaba el cabildo regularmente cada año, tiempo que duraba el contrato. La subasta la ganaba, regularmente, quien ofertara los precios más bajos de venta, aunque el cabildo analizaba la oferta y decidía si ésta era plausible. La oferta se conocerá como 'postura' y la mejora de la oferta, como 'baxa'.

Habrá excepciones a la duración del contrato como que algún encargado del abasto renunciase a su obligación, situación que será más habitual conforme la disposición de ganado sea más escasa ${ }^{8}$. O bien, en el caso de que alguien "abaxase" la postura durante el período corriente del contrato del obligado, es decir, ofreciese un menor precio de venta, en tal caso la Audiencia analizaba la oferta posterior y podía revocar el contrato de la obligación para concederlo al nuevo postor. Para el caso de la ciudad de México existen diversos testimonios de que lo anterior ocurría habitualmente. Por ejemplo, en agosto de 1533, el entonces regidor en la capital del virreinato, Gonzalo Ruiz, señalaba: "porque la republica no resciba daño e agrabio en comprar la carne a mas precio" "que en adelante se pesase la carne según una baja posterior. El puesto de obligado, que se había otorgado a Gonzalo Gómez Castillejo, fue entregado a un nuevo postor, un vecino de la ciudad de nombre Bartolomé de Morales. La condición

7 HeRnÁNDEZ ÍÑIGO, 2006, p. 75.

8 Quiroz, 2003, pp. 191-193.

9 Acta del 1-VIII-1533. ACCM, libro III, pp. 45-46, Matesanz, 1965, p. 551. El autor señala que no será hasta 1531, cuando la obligación se comenzó a poder destituir, pero en 1528 hay constancia de que Hernán Alonso y Bartolomé de Morales, son sustituidos por Bartolomé Quemado, sólo veinte días después de haberles sido otorgada la obligación. Quemado había "abaxado" los precios del arrelde de vaca y de puerco a casi la mitad del precio que los anteriores habían ofertado. Actas del 9-III y 29-III-1528. ACCM, libro I, pp. 161 y 165. 
y el beneficio del obligado sustituido, consistió en que Morales asumió las pérdidas de Gómez en relación al precio que éste había pagado por su ganado.

Aunque la subasta era anual, el obligado podía volver a hacerse con el cargo si al cabo de su contrato, en la siguiente adjudicación, su oferta volvía a ser la más baja. La subasta anual era la manera en que funcionaba la obligación de la carne en Castilla en el siglo XV. Para la centuria siguiente ya veremos en la Nueva España, contratos por dos años ${ }^{10}$.

El empresario que pujaba por el puesto de obligado y que no tenía que poseer reses necesariamente, ofertaba a la baja y ofrecía cierto peso de carne por una cantidad fija de dinero; es decir, su oferta o postura era una relación precio-peso que debía mantenerse invariable durante todo el tiempo que durase su contrato. La medida de peso durante el siglo XVI será el arrelde, equivalente a cuatro libras ${ }^{11}$, pero las monedas utilizadas en estas transacciones, variarán. Habrá posturas hechas en tomines, en reales y en maravedíes de oro, en las que el tomín y el real de oro serán equivalentes entre sí y corresponderán a su vez a 56,35 maravedíes cada uno ${ }^{12}$.

Los precios de la carne fluctuarán y disminuirán a lo largo de la primera mitad de centuria, llegando a ser los más bajos alrededor de 1540-1542 ${ }^{13}$. Para los años de 1525 a 1528, en la ciudad de México encontramos que regularmente la postura para la carne de vaca, estará entre los dos reales y medio y los cuatro por arrelde de vaca o de carnero, y entre los 28 maravedíes y un real por arrelde de cerdo ${ }^{14}$. Para la siguiente década, las posturas para la vaca, el carnero y el cerdo serán muy similares e irán desde los nueve hasta los diecisiete maravedíes por arrelde. Los precios continuarán bajando y el arrelde de vaca se llegará a vender hasta en 4 maravedíes en $1542^{15}$. Esta tendencia se detendrá cuando la 'sorprendente multiplicación de los ganados' citada por Chevalier, también llegue a su cenit y se detenga. Hacia 1565 se hablará de las diversas circunstancias posibles de este hecho, entre ellas, que los indios, aficionados cada vez más al consumo de carne de res, habrían contribuido a la disminución de las vacadas. De ello hablaremos más adelante.

Una ordenanza publicada el 17 de enero de 1525 mandaba que a partir del inicio del año se debía sacar a pregón la postura de la carnicería, haciendo pública mención de la subasta los domingos y los días de guardar. Finalmente, el abasto de carne se remataba por los días de carnestolendas, es decir, desde mediados de febrero hasta principios de marzo. Desde entonces y hasta el día de "la pascua florida", el obligado tenía todo el tiempo de la cuaresma para proveerse del ganado necesario y asumir su compromiso $^{16}$. De esta manera, el contrato duraba desde que terminaba la cuaresma hasta que se adjudicaba nuevamente la obligación hacia las fechas del carnaval. En

10 Poder que otorga Doña Isabel Ruiz de Medina a Matías Ruiz de Sarabia para las diligencias del abasto, 16-IV-1568. Archivo General de la Nación, México (en adelante AGN), Instituciones Coloniales, Ayuntamiento, Abasto y panaderías, vol. 3, exp. 18, ff. 176 - 205. Quiroz, 2003, p. 193.

11 La libra carnicera equivalía al doble de la normal, es decir, unos 900 gramos. Domínguez OrTIZ, 1992,

p. 85, Diccionario de la Real Academia Española.

12 Matesanz, 1965, pp. 555-556.

13 Chevalier, 1999, p. 184.

14 Actas del 26-IX-1525, 25-III-1526, 4-III-1527 y 9-III-1527. ACCM, libros I y II.

15 Actas del 31-VII-1536, 28-III-1538, 11-III-1539 y 21-III-1542. ACCM, libro III.

16 Acta del 17-I-1525. ACCM, libro I, p. 27. 
la subasta, debía estar presente, por lo menos, un alcalde ordinario y dos diputados regidores ${ }^{17}$.

El así llamado obligado de la carne, tenía en aquellas ciudades que poseían permisos para establecer carnicerías bajo esta figura legal, la responsabilidad de comprar a los criadores de ganado la cantidad suficiente de ganado vivo o en pie, para después matarlo y abastecer de carne a las carnicerías de su jurisdicción. La figura de la obligación podía ser individual o bien, compartida entre dos o más individuos que se repartían ganancias y responsabilidades. También sabemos que para el siglo que nos ocupa, podía existir una obligación por cada tipo de carne. En 1530 existe constancia de que el obligado en la capital, sólo hacía las posturas que le convenían, incluso dejando fuera la carne de vaca, para la cual, el obligado señalaba que la ciudad "hiciera y proveyera como mejor le pareciera". En este caso Antón de Carmona se comprometía a dar el arrelde de carnero a tomín de oro y el de puerco a real de oro, además, ofrecía que cualquier criador de cerdos y carneros pudiera pesar su ganado en la carnicería para poder dar abasto al mismo precio que el de su postura, con la única condición de pagar al tajador su salario ${ }^{18}$.

A lo largo del siglo XVI veremos que la obligación se irá estabilizando y que las responsabilidades se harán más claras. Como en el ejemplo anterior, se expedirán licencias para que ciertos particulares pesen y vendan su propia carne en las carnicerías, siempre y cuando la venta se realice al precio de la postura del obligado ${ }^{19}$. También habrá períodos en los que ante la falta de "quien se obligue a dar carne de vaca a honestos precios", el Ayuntamiento disponga que sean los criadores los que pesen y den abasto de este producto a los precios que fijaba el Cabildo ${ }^{20}$. O bien, se exhortará so penas de no hacerlo, a que los vecinos de la ciudad que posean ganado, lo lleven a las carnicerías en períodos en los que no hubiese obligado ${ }^{21}$.

En consonancia con lo anterior, quizá en previsión de que el obligado no fuese capaz de dar abasto, pero sobre todo, en previsión de que ante la escasez se desatase la venta ilegal; en la ciudad de México, los meses de junio, septiembre y diciembre del año en que el obligado tenía hecho el contrato, los criadores de ganado estaban autorizados a pesar su carne y venderla en las carnicerías ${ }^{22}$.

Lo anterior nos indica que la obligación no sólo estuvo fuertemente regulada en favor de prevenir el desabasto, sino que los cabildos tuvieron claramente la previsión de que el estanco fuese "en pro y beneficio de la República", velando sin duda, más por los intereses de los vecinos que por los del monopolista que se encargaba del abasto. El obligado, como se ha visto, manejaba un monopolio, pero en la práctica, no gozaba exactamente de los privilegios que éstos solían tener.

17 Acta del 20-III-1533. ACCM, libro III, p. 20

18 Acta del 14-IX-1532. ACCM, libro II, p. 81.

19 Acta del 15-X-1526. ACCM, en la que se autoriza a Andrés de Tapia, regidor ordinario de la ciudad de México a que pese carne en las carnicerías de la ciudad. La postura estaba establecida en cinco reales por arrelde (cuatro libras) de carnero y la licencia se extendía a cualquier persona que "abaxase" la postura.

20 Acta del 2-IV-1538. ACCM, libro III, p. 128. El Cabildo dispone también que se compre al obligado un esclavo negro llamado Francisco, que aquél tenía trabajando como tajacarne en la carnicería.

21 Acta del 17-IV-1538. ACCM, libro III, p. 127.

22 Acta del 25-III-1526. ACCM, libro I, p. 81. 
Recordemos que el modelo de adjudicación del beneficio del estanco no es exclusivo de la venta y distribución de carne de vaca y carnero. El modelo de la subasta será utilizado en Nueva España, a semejanza del modelo castellano, en ámbitos varios del abasto de bienes de consumo tales como el pescado, el aceite o el pan ${ }^{23}$, para cuya provisión, el ayuntamiento subastó concesiones de venta a los comerciantes respectivos, convirtiendo el abasto de estos productos en un estanco no dependiente de la corona y con estrictos mecanismos de vigilancia. La obligación apremiaba al empresario a sortear las dificultades que pudieran surgir durante el período, tal como la escasez de animales. A pesar de las previsiones señaladas anteriormente, el obligado se comprometía con el Cabildo a mantener sus precios, pero los criadores sólo hacían tratos de palabra con el obligado, de manera que éste último era el único que respondía ante la Justicia si finalmente era incapaz de afrontar las condiciones de su contrato. Aunque el negocio de las carnicerías, así como la figura de la obligación estaba en manos de unos cuantos, amén de lo que se ha mencionado, no debe pensarse que este negocio constituía siempre una empresa beneficiosa ${ }^{24}$.

Entre los mecanismos restrictivos se encontraban, que el notario del cabildo debía entregar reportes periódicos al virrey en los que se informaba sobre las condiciones del mercado de la carne, asimismo, los oidores estaban facultados para revocar licencias cuando la ocasión lo requería ${ }^{25}$; en mayor medida, serán retiradas cuando criadores y obligados, quizá en confabulación, intenten sacar de las estancias, previa petición de permisos para ello, al ganado enfermo, viejo o inútil que ofrecía la oportunidad de ser vendido en el estraperlo ${ }^{26}$. A partir de la insistencia en la legislación sobre fraudes cometidos, cabe pensar que la venta ilegal y el engaño en pesos y precios, fuese habitual. El abastecedor, al contraer la obligación, dejaba como fianza sus "bienes muebles e rayzes ávidos e por haber" para guardar y cumplir las condiciones de venta que ofrecía ${ }^{27}$.

Para cumplir sus compromisos, los obligados debían asegurarse la provisión de animales por parte de estancieros o bien, de tratantes de ganado. Como es de suponer, el obligado no despachará las carnicerías ni se encargará de labores como el cuidado y pastoreo de los animales. La matanza del ganado, que debe efectuarse única y exclusivamente en el matadero, así como el transporte de la carne hasta las carnicerías, también será labor de ciertos empleados del obligado. En el siglo XVI, encontraremos que tanto pastores como encargados de la matanza y el transporte, serán frecuentemente indios, no así, encargados de las carnicerías. La figura de los "indios carniceros" como "aquellos que sirven de matar reses y cortar carne a los españoles", la encontramos en La Monarquía Indiana de Torquemada, cuando se refiere a las limosnas de menudos de vaca y carnero que este gremio hacía al Convento de San Francisco en la ciudad de México todos los sábados ${ }^{28}$.

23 Monsalvo, 1988, p. 459.

24 Quiroz, 2003, p. 193. La autora lo señala para el siglo XVIII en relación a los obligados de la carne en la ciudad de México.

25 Dussenberry, 1948, p. 38.

26 Ventura Beleña, 1991, p. 25. Auto acordado en noviembre de 1583.

27 Acta del 25-III-1526. ACCM, libro I, p. 81.

28 Torquemada, 1975, p. 217. 
En la carnicería, el cortador, quien también pesaba la carne, no podía pesar carne muerta de más de tres días y debía vestir un delantal limpio y mantener la carne en las escarpias tapada con paños. Cuando se efectuaba el peso, un diputado que ejercía el cargo de fiel, debía estar presente y verificar el peso de la carne ${ }^{29}$.

En adelante veremos el caso de Tlaxcala. Provincia que tanto en el tema del abasto de la carne, como en otros muchos aspectos, presentó situaciones particulares derivadas del hecho de haber mantenido cierta independencia política durante este siglo. Es importante recordar que el cabildo indio, compuesto por miembros de los cuatro señoríos que conformaban el gobierno de la Tlaxcala precortesiana, asumió gran parte de las funciones políticas de la provincia una vez establecido el gobierno virreinal. Los tlahtoque, señores principales de cada cabecera: Ocotelulco, Tizatlán, Quiahuiztlan y Tepetícpac, se erigieron en regidores perpetuos y rotativamente, en gobernadores de Tlaxcala ${ }^{30}$. En igualdad de condiciones, la gubernatura se compartía con un par español que representaba los intereses del gobierno virreinal.

El establecimiento de un gobierno indio, fue el privilegio más importante de los otorgados por el rey de España en razón de la temprana alianza tlaxcalteca con Cortés en la conquista de México. Tlaxcala, subordinada únicamente a la corona de Castilla como parte de los privilegios señalados, a través del cabildo de naturales, consiguió mantener la autonomía política de su territorio y mantenerse fuerte frente a otros poderes regionales como Puebla ${ }^{31}$.

Como consecuencia de lo señalado, en Tlaxcala, el sistema de abasto de carne fue entregado a las autoridades indias. Pero pronto, a partir de 1550, según observaciones de las autoridades españolas, el cabildo de naturales comenzó a presentar dificultades para mantener en orden este abasto.

\section{LA PROHIBICIÓN DE VENTA DE CARNE DE 1568 Y EL ABASTO EN TLAXCALA EN EL SIGLO XVI}

En julio de 1568, la Real Audiencia de México prohibía que hubiese carnicerías de vaca y oveja en pueblos de indios ${ }^{32}$. La prohibición, que estaba relacionada con asegurar el abasto de carne en ciudades de españoles y con la contención de las matanzas ilegales de ganado, según señala Gibson, no perseguía en realidad acabar con el sacrificio del ganado vacuno sino arrancar del control de los indios el negocio de la carne $^{33}$.

Registros en actas de cabildo de Tlaxcala de 1547, indican que el abasto de carne estaba en manos de las autoridades indias. En dichos registros se señalan las penas

29 Acta del 7-V-1527. ACCM, libro I, p. 129.

30 Assadourian, 1991b, pp. 55-60.

31 Martínez Baracs, 2008, p. 80.

32 Poder que otorga Doña Isabel Ruiz de Medina a Matías Ruiz de Sarabia para las diligencias del abasto, 16-IV-1568. AGN, Instituciones Coloniales, Ayuntamiento, Abasto y panaderías, vol. 3, exp. 18, ff. 176 - 205. En el documento figura la copia de la Real Provisión de 1568; Acta del 19-VII-1568. ACCM, libro VII, p. 404. Ventura Beleña, 1991, p. 53. El autor señala como fecha de la prohibición el 17 de julio de 1578, fecha errónea si se toma en cuenta que esta provisión ya estaba incluida en las ordenanzas de la Mesta de 1574.

33 Gibson, 1991, p. 151. 
por no vender por peso la carne, y se establece el monto del impuesto de colocar el sello de la ciudad a los pesos y pesas con que los carniceros debían medir los productos que vendían ${ }^{34}$. La prohibición, luego recopilada en las Ordenanzas de la Mesta de 1574, señalaba que debido a los hurtos de ganado en pueblos de indios, se corría el riesgo de la disminución acelerada de los animales y con ello, de que no hubiese persona "que se obligase al abasto de las carnicerías de la ciudad de México y de otras principales de españoles" 35 .

Otro argumento para la prohibición, habría sido que hacia la década de 1570, los indios se habían aficionado a la carne de res pero que no contribuían en la cría del ganado bovino. Los españoles consideraban que los indios consumían carne en exceso y al finalizar la década de 1560, su afición se habría convertido en una de las causas de la disminución de las cabañas ${ }^{36}$.

Sin poder afirmar lo anterior, la ganadería mayor al parecer no fue una actividad por la cual los indios se interesaran. La posibilidad de que criasen cualquier tipo de ganado se estableció desde 1551 y fue incluida en la Recopilación de Leyes de Indias de $1680^{37}$. La escasez de registros de esta actividad ganadera por parte de indios, probablemente tenga que ver con el hecho de que, para criar ganado mayor en cantidades comercialmente importantes, tal como sucede en nuestros días en el caso del régimen extensivo, era indispensable tener caballos. Sobre la posesión y uso de ganado caballar, a pesar de las numerosas licencias que fueron otorgadas ${ }^{38}$, sí hubo restricciones severas para los indios ${ }^{39}$.

La cría ovina, en cambio, llegó a tener alguna repercusión comercial entre los indígenas, hasta el punto de que el mismo cabildo de Tlaxcala se hizo con una cabaña importante. En 1548, encontramos ventas por parte de los miembros del ayuntamiento de 580 carneros de su pertenencia. En el caso de estos rebaños, sabemos también que la cría fue supervisada por españoles ${ }^{40}$. La prohibición, al no mencionarla, dejaba

34 Celestino, Valencia y Medina, 1985, pp. 237, 243-244.

35 Ventura Beleña, 1991, p. 53. Capítulo 64 de las Ordenanzas de la Mesta. Texto completo en pp. 2774; Para el caso de Cholula, similar al de Tlaxcala por tratarse de un pueblo de indios, Castillo, 2001, pp. $220-222$.

36 Chevalier, 1999, p. 192.

37 "No se prohíba a los indios, que puedan criar todas, y qualesquier especies de ganados mayores, y menores, como lo pueden hacer los Españoles sin ninguna diferencia, y las Audiencias, y Justicias les den el favor necesario". RECOPILACIÓN..., Tomo II, libro VI, título I, ley XXII.

38 Licencia para montar a caballo y portar hábito de español a Don Juan de Contreras, indio de Tlaxcala, 1591. AGN, Instituciones Coloniales, Real Audiencia, Indios, vol. 3, exp. 821, f. 195v.; Licencia para montar a caballo a Juan de Paz, indio de Tlaxcala, 1589. AGN, Instituciones Coloniales, Real Audiencia, Indios, vol. 4, exp. 65, f. 20v.; Licencia para montar a caballo a Don Jerónimo de Treviño, indio de Tlaxcala, 1590. AGN, Instituciones Coloniales, Real Audiencia, Indios, vol. 4, exp. 395, f. 127; Licencia para montar a caballo y portar hábito de español a Don Juan Díaz, indio de Tlaxcala, 1591. AGN, Instituciones Coloniales, Real Audiencia, Indios, vol. 5, exp. 658, f 250v.; Licencia para montar a caballo a Pedro Delgado, indio de Tlaxcala, 1593. AGN, Instituciones Coloniales, Real Audiencia, Indios, vol. 6, exp. 601, f. 160.

39 “...Que no tengan los yndios cauallos mullas ni armas: so pena de muerte. Aueys de defender y proybir, que ninguno sea osado de dar vendido ni dado ni en otra manera que pueda venir a su poder a ningun yndio de la dicha tierra ni fuera della cauallo ni yegua por el ynconviniente que dello podria suceder en haserse los yndios diestros de andar a cauallo, so pena de muerte y perdimiento de bienes: y ansi mesmo provereys, que no aya mulas: porque todos tengan caualllos y terneys cuydadu, que assi se cumpla, y lo mesmo prouereys en las armas por la via, y pena que vos pareciere...". PUGA, 1985, ff. 42v-43r.

40 Celestino, Valencia y Medina, 1985, p. 264. 
fuera la carne de cerdo, ganado en cuya cría los indios también participaron. Para 1576, el virrey hacía explícita la permisión de la cría y venta del cerdo, indicando al alcalde mayor de Tlaxcala que permitiera la matanza de cerdos por parte de los indios, asimismo, que les permitiese vender su carne al precio que la justicia acordara ${ }^{41}$.

Para la centuria que nos ocupa, se sucederán ordenamientos jurídicos de muchos tipos. Disposiciones dictadas desde la metrópoli con carácter general para los territorios ultramarinos, o para la Nueva España en particular, mejor conocidas como cédulas; disposiciones dictadas por las autoridades locales como Real Audiencia o Virrey, tales como ordenanzas, decretos o despachos. Alcaldes y corregidores, por su parte, dictarán órdenes para que se cumplan las disposiciones emanadas de otras autoridades de mayor jerarquía, además de administrar justicia civil y penal. Finalmente y de gran interés para comprender el funcionamiento de diversos aspectos locales, las autoridades municipales reunidas en el cabildo, resolverán cuestiones relativas a la vida diaria de su jurisdicción ${ }^{42}$. Este tipo de órdenes locales perfilarán el estado de la cuestión en materia de abasto de carne en la provincia de Tlaxcala.

Dos años después de que fuese prohibida la venta de carne de vaca y oveja en los pueblos de indios, el virrey Martín Enríquez redactaba la siguiente ordenanza:

Por quanto la dicha real audiencia e al tienpo que governo y por mi esta ordenado y mandado que no haya carnecerias en pueblos de yndios desta nueva españa so ciertas penas y por parte de los naturales de la ciudad de tlaxcala me a sido fecha rrelacion que en ella se padesce a causa de no la aver por que en la dicha ciudad y su provincia ay seys conventos de Religiosos y cantidad de españoles que biben e rresiden en ella y muchos yndios prencipales que tienen necesidad de la comer y la ynvian a comprar a la ciudad de los angeles de que resciben vexacion y me pidieron que pues como hera notorio avian servido siempre a su majestad en la conquista desta nueva españa como despues fiel e legalmente como buenos vasallos mandase que en la dicha ciudad obiese la dicha carniceria o al menos se diera licencia para que en ella se pudiesen matar y vender una cantidad moderada de novillos e carneros para que no se padezca la dicha necesidad y por mi visto y consideración a lo susodicho por la presente doy licencia y facultad para que en la dicha ciudad de tlaxcala se pueda matar y vender cada una semana hasta cantidad de veinte novillos y otros veinte carneros sin enbargo de lo que encontra está proveido porque hasta la dicha cantidad yo suspendo el efecto de lo asi mandado dexandolo en su fuerza y vigor ${ }^{43}$.

A su entender, el crecimiento de los vecinos españoles y la afición de los indios nobles por la carne, hacía necesaria una modificación en la prohibición. Es de suponer que la necesidad de consumo de carne de algunos vecinos de Tlaxcala, llevara a la venta del producto y que el virrey Martín de Enríquez intentara subsanar con esta enmienda, no sólo la necesidad, sino también la distribución ilegal. Es interesante

41 Gibson, 1991, p. 151. El Virrey Martín de Enríquez al alcalde mayor de Tlaxcala para que no impida a los indios matar puercos y vender su carne, 4-IV-1576. AGN, Instituciones Coloniales, Gobierno Virreinal, General de Parte, vol. 1, exp. 816, ff. 158v-159.

42 GonZÁlez, 1985, pp. XXVI-XXVIII.

43 Licencia del Virrey Martín Enríquez para matar y vender veinte novillos y veinte carneros en la ciudad de Tlaxcala, 30-I-1570. Archivo Histórico del Estado de Tlaxcala (en adelante AHET), Fondo Histórico, Colonial, caja 3, exp. 20, f.1. 
recordar que la carne, durante la Edad Moderna en los reinos hispanos peninsulares, es un producto cuyo consumo está directamente relacionado con el estatus social. Así, en Castilla habrá carnicerías separadas para pecheros y para hidalgos, quienes adquirían el producto sin pagar la sisa de la carne ${ }^{44}$, entendiendo que la exención del pago de este impuesto repercutía en que estuviesen mejor alimentados y por tanto, se pudieran hacer cargo de las eventuales necesidades de defensa que tuviera la ciudad. De esta manera, no tendría igual importancia abastecer una ciudad llena de hidalgos españoles como la capital del virreinato, que mantener el abasto en un pueblo de indios. No se trataba de procedencia étnica, sino de origen social. Por tal hecho, el permiso de venta de carne, hacía énfasis en que tanto españoles como principales tlaxcaltecas tenían "necesidad de la comer" y se entendía que en época de escasez, tenían prioridad sobre el resto de la población.

En este caso, el mecanismo de provisión de carne consistió en rematar el puesto de la carnicería al mejor postor; pero no como en el caso de la obligación, que como se ha visto, se remataba en quien ofertara la mejor postura de venta. El contratista se hacía con un licencia directamente proveída por el virrey, es decir, se hacía con un asiento, un monopolio no dependiente de la corona ni de las autoridades locales, sino de las virreinales ${ }^{45}$.

Al parecer, el remate provocó que fuesen los regatones ${ }^{46}$ los que se hicieran con el negocio de la venta de carne, o bien, comerciantes a quienes no se les vigilaba debidamente y cometían reiterados fraudes con los precios, los pesos y la procedencia del ganado. Para controlarlos, fueron puestos veedores. Los veedores de carnicerías ya habían sido puestos en el oficio en la ciudad de México desde $1551^{47}$ y para 1574 , en las Ordenanzas de la Mesta, será colocado en cada carnicería un veedor español cuyo sueldo debía pagar bien el obligado o bien, el asentista de la carne. Su función era dar fe del número de reses muertas, de los hierros de donde provenían, de que los cueros coincidieran con las reses sacrificadas y de revisar los papeles de la venta del gana$\mathrm{do}^{48}$. El veedor, cuyo sueldo corría a costa de quien debía controlar, no siempre fue un funcionario de fiar. El marqués de Villamanrique, en un informe a Felipe II redactado en 1585, ya denunciaba que "[cierto veedor] estava siempre asistente dela comunicacion del obligado venia a dexarse cohechar y passar por los daños sin castigallos"49.

En 1683, se acordará que se retiren y no se nombren más de estos "jueces de carnicería" que asistían como veedores. La supervisión de estas actividades se dejará en

44 La sisa será el impuesto que, o bien se incluirá como un extra en el precio o bien se cobraba indirectamente al disminuir la cantidad de carne que se entregue al consumidor, en este último caso serán los fieles quienes calibren las pesas para cobrarlo. Acta del 7-IV-1564. ACCM, libro VII, p. 183; DomínguEZ, 1973, p. 33. En Sevilla no había esta separación en las carnicerías, pero a los hidalgos se les devolvía la llamada "blanca de la carne", una blanca por cada libra de carne que pagasen. DOMíNGUEZ, 1992, p. 155.

45 Aunque este mecanismo de abasto difería de la obligación en algunos de sus aspectos de control, en la documentación corriente de instrumentos públicos, encontraremos que se le llamará obligación. La distinción se hará por la introducción de la palabra 'licencias' en los mismos documentos.

46 El regatón era el comerciante que vendía al por menor los productos que compraba al por mayor.

47 García-Abásolo, 1983, p. 168.

48 Ventura Beleña, 1991, p. 37.

49 Carta del Virrey Marqués de Villamanrique, 22-IV-1587. Archivo General de Indias, Sevilla (en adelante AGI), México, 21, nº 9. ff. 5 y 6. 
manos de la justicia de los cabildos quienes, sin tener un salario extra por esta actividad, sólo podían percibir la parte proporcional de las denuncias que hicieran sobre el funcionamiento fraudulento del asiento ${ }^{50}$.

Con respecto a que el abasto en los pueblos de indios lo monopolizaban los regatones, Villamanrique señalaba en el mismo documento:

de permitir los remates destas carnicerías a las justicias avia mill negociaciones porque nose hazian sino en los recatones de ganado y estos como ombres por la mayor parte desalmados aunque ofrescian de dar mucha cantidad de carne porque rematar en ellos hecho el remate davan la que querían y azian mill engaños a los yndios ${ }^{51}$.

El informe señalaba que tanto Martín de Enríquez como Suárez de Mendoza, conde de La Coruña, habían mantenido la figura del remate al mejor postor y el sistema de licencias para el abasto de carne en los pueblos de indios y que en consecuencia, se habían creado nuevos oficios de los cuales se aprovechaban aquellos a quienes los virreyes habían otorgado los permisos de venta.

En efecto, el estanco de la carne bajo esta figura de licencias, evitaba que fuera el cabildo de naturales el que administrara las ganancias del monopolio. A este respecto es interesante señalar que no será hasta el siglo XVIII, en 1716, cuando la regulación y el abasto del comercio en el que se incluían los monopolios de la carne y el pan, pasarán al control absoluto del cabildo indio, no sin importantes reclamos por parte del entonces gobernador español de la provincia, quien vio sumamente afectada su jurisdicción política ${ }^{52}$. Por otra parte, dichas licencias no serán otorgadas a miembros del cabildo indio. Esta situación, que fue común en la ciudad de México no se verá en Tlaxcala, donde los permisos de venta se otorgaban a comerciantes españoles, incluso residentes en la capital o en otras localidades. Sin embargo, algunos mestizos de la élite sí tuvieron participación en el negocio de la carne, como el caso de Juan y Diego Muñoz Camargo, hijos del conquistador homónimo, quienes se vieron involucrados en ventas de ganado que tenían apacentado en estancias de su propiedad en la década de $1570^{53}$.

El cabildo indio en lo sucesivo, interpelará a la Real Audiencia para que la prohibición de la venta de bovino sea restituida. La primera revocación de la licencia señalada, mediante la cual se permitía el sacrificio de 20 novillos y 20 carneros por semana, se dictará en 1571. El 16 febrero, un mandamiento del virrey Martín de Enríquez dirigido al alcalde mayor de Tlaxcala, prohibía que en esta ciudad se matase, pesase ni vendiese carne de vaca. Sobre las ovejas, es de notar, que no se menciona nada. La orden señalaba que habiendo hecho queja el cabildo de esta ciudad de que las carnicerías de vaca allí establecidas ocasionaban daño a los indios, quedaba revocada la licencia que para ello había sido otorgada por el mismo virrey ${ }^{54}$.

50 Ventura Beleña, 1991, pp. 21 y 22.

51 Carta del Virrey Marqués de Villamanrique, 22-IV-1587. AGI, México, 21, nº9. f. 5.

52 Martínez Baracs, 2008, p. 423.

53 Hernández Rodríguez, 1988, vol. 1, pp. 42 y 282.

54 Mandamiento de Martín de Enríquez, 16-II-1571. AHET, Fondo Histórico, Colonia, caja 3, exp. 23 , f. 1. 
Si el impulso de los miembros del cabildo indio de Tlaxcala hubiese sido únicamente apropiarse del estanco de la carne, las peticiones habrían ido directamente en el sentido de la eliminación del estanco de manos de españoles, o bien, de devolver la administración de la obligación al cabildo; sin embargo, tres años después de la prohibición, los indios seguirán pidiendo directamente que no se permita la carnicería de vaca. Ello nos habla quizá, no de la búsqueda de apropiación del negocio, sino del intento por solucionar un problema mayor del que los principales de esta provincia ya tenían bastante conocimiento, a saber, el de la invasión de sus tierras por parte de ganaderos españoles.

En el año 1570 el cabildo había realizado todas las diligencias posibles para hacerse oír en lo tocante a las apropiaciones ilegales del terreno. Primero, intentando hacer valer los privilegios que habían obtenido de su alianza con los conquistadores y entre los cuales se encontraba la inviolabilidad territorial de esta provincia indígena. En vista de no conseguir que los ganaderos fueran expulsados de sus territorios, sus peticiones de justicia comenzaron a parecer súplicas. Sin embargo, en esta misma década, habían conseguido una victoria efímera. A diferencia de los demás pueblos indios que vieron mermado su espacio, los tlaxcaltecas consiguieron que en su provincia la expansión territorial hispana se contuviera y que fueran pocas las mercedes de tierra otorgadas por el gobierno virreinal ${ }^{55}$.

Creemos que el negocio de la carne vacuna, que involucraba la cría del ganado mayor, como consecuencia de una ardua lucha emprendida desde hacía tres décadas por el cabildo tlaxcalteca, en el sentido de expulsar a los ganaderos, era visto para 1570 ya como una amenaza. Es posible que los indios de Tlaxcala buscaran mantener la prohibición como un último recurso al avance ilegal de las estancias, aunque en principio, el veto a la venta de carne tuviese otros motivos. Mientras existieron las licencias particulares, la fecha más temprana en que comenzamos a tener noticia sistemática sobre el abasto de carne de vaca en Tlaxcala es 1572 .

El 14 de febrero de este año, Gazpar Saluago y Andrés Ruiz formaron la compañía para el abasto de la carnicería de vaca de Tlaxcala ${ }^{56}$. Para ese mismo año, Saluago cerrará un trato con Cristóbal Barrios en el que este último traería ganado de la región de los Chichimecas y lo apacentaría en Aguascalientes. Por su parte, Andrés Ruiz negoció la compra de ganado con Tomás Hernández y dos años más tarde con Miguel Morales ${ }^{57}$. Ambos, muy probablemente, tratantes de ganado.

En 1573, el español Juan de Arrieta Viscaíno se comprometerá con Andrés Ruiz como cuidador de su ganado ${ }^{58}$, por su parte, los indios Antón Sanchez y Hernando Sánchez, hermanos y Diego Hernández, se comprometen a trabajar como carniceros para el asentista. El trabajo de estos últimos, consistirá en transportar los jueves de cada semana el ganado al matadero, sacrificarlo la madrugada del viernes, desollarlo, cuartearlo y acarrearlo a la carnicería. Por la mañana del sábado, dando razón de

\footnotetext{
55 Assadourian, 1991a, p. 126.

56 Hernández Rodríguez, 1988, vol. 1, p. 17.

57 Ibídem, pp. 17 y 129.

58 Ibídem, p. 86.
} 
todos los cuartos, debían entregarlo a Andrés Ruiz ${ }^{59}$. Será importante que el ganado no se mate antes de la madrugada del viernes, de ser así, existía la posibilidad de que el mismo viernes, contrario a las disposiciones canónicas, se consumiera la carne, además de que para el domingo podía estar estropeada ${ }^{60}$.

El siguiente año, García Fernández Becerra será el encargado de cuidar el ganado que Andrés Ruiz tenía apacentado en Atlangatepec como parte de la provisión del abasto de las carnicerías de la provincia. Por un sueldo de cuatrocientos pesos de oro común al año, Fernández se comprometía a proveer los caballos y la gente necesaria para cuidar del ganado. Entre sus obligaciones se encontraban la de no poder cambiar ni vender ninguna res, pagar cinco pesos de oro por cada res extraviada, así como informar al obligado de cada res muerta accidentalmente. En ese caso, Fernández daba por pagada la res muerta entregando únicamente el cuero del animal ${ }^{61}$. Ruiz también tendrá a su servicio a Cristóbal de la Mora, mestizo, que le sirvió como vaquero de sus rebaños bovinos en la segunda mitad de 1574 .

En 1580, gobernador y alcaldes indios de Tlaxcala arriendan al indio Bartolomé de Paz, una casa para la carnicería. El mismo año se le concederá una licencia excepcional para que suministre el abasto de oveja de la ciudad para lo cual había adquirido mil carneros ${ }^{62}$.

La figura del indio carnicero será habitual durante todo el siglo. Para 1599, en Tlaxcala, Baltasar Tzaquanpantzi y Alonso Tzimatzin, indios carniceros que habían servido tanto en el matadero como en la carnicería, juraban en un testimonio, que habían visto siempre pesar por parte del encargado de la administración de las carnicerías de Tlaxcala, Francisco Agustín, en nombre del obligado Álvaro Degrado, la cantidad justa de carne. Asimismo, testimoniaban que el sábado, día en que se pesaba el abasto, habían visto siempre afieladas las pesas ${ }^{63}$. Álvaro Degrado, quien era natural de la ciudad de México, tenía para este año la obligación de las carnicerías de Tlaxcala. En 1576, sabemos que Juan Muñiz, mestizo, vecino de Texcoco, poseía la licencia del abasto del carnero en la provincia ${ }^{64}$. Y para 1589 será Mateo de Mauleón el abastecedor. Este último personaje, con una larga carrera en el negocio de la carne, había obtenido la licencia del abasto en Cholula y la obligación en Puebla en $1576^{65}$ y en 1587 se encargaba del abasto de vaca en Tepeaca ${ }^{66}$.

\footnotetext{
59 Concertación con Andrés Ruiz, obligado de las carnicerías de vaca de Tlaxcala, 5-IV-1573. AHET, Registro de Instrumentos Públicos, Colonia, libro 1, f. 297.

60 Acta del 22-IX-1533. ACCM, libro III, p. 52.

61 Obligaciones de García Fernández Becerra con Andrés Ruiz, 23-XII-1573. AHET, Registro de Instrumentos Públicos, Colonia, libro 1, ff. 377v-378.

62 Hernández Rodríguez, 1988, vol. 2, pp. 403 y 409; Gibson, 1991, p. 151.

63 Microfilm de la Biblioteca Nacional de Antropología e Historia (en adelante BNAH), 3-V-1599. Serie Tlaxcala, rollo 1 .

64 Don Martín de Enríquez a Juan Muñoz, 10-V-1576. AGN, Instituciones Coloniales, Gobierno Virreinal, General de parte, vol. 1, exp. 910, ff. 169v y 170 .

65 MotTA, 2006, p. 136.

66 Licencia a Mateo de Mauleón para matar carne de novillo en Tepeaca. Jurisdicción Oaxaca, 19-III-1587. AGN, Instituciones Coloniales, Gobierno Virreinal, General de parte, vol. 3, exp. 136, f. 65. El documento señala Tepeaca en la jurisdicción de Oaxaca. En la cuarta Carta de Relación de Cortés ciertamente existe noticia sobre la fundación de Tepeaca en Oaxaca, en la que se asienta una guarnición mexica. La información sobre el abasto podría sin embargo referirse a Tepeaca, Puebla.
} 
La prohibición del estanco será suprimida en 1583. Aunque tal como se ha visto que funcionaba el abasto en Tlaxcala, mediante licencias y no exactamente como una prohibición, se puede decir que el funcionamiento de las carnicerías en esta fecha será finalmente equiparado al de la obligación, la figura del abasto de carne que existía en la república de españoles. A este respecto, recopilado por Ventura Beleña tenemos la siguiente ordenanza:

Que se quiten y no se den en adelante licencias á personas particulares para que ellas y no otras puedan tener Carnicerías y vender carne en los Pueblos sin guardar postura $[\ldots]$ y entonces se traigan en público pregón las Carnicerias ante las Justicias de los Pueblos para las baxas que hubieren de hacerse guardando y ajustando el precio sin que se venda a ojo y sin pesar ni las reses en pie ni en las casas, sino en las carnicerías $^{67}$.

La supresión de las licencias seguía sin permitir al Cabildo indio participar del negocio de la carne ${ }^{68}$. Un auto dictado el siguiente año, inhabilitaba el acceso a otro cargo público a cualquier miembro que perteneciendo al cabildo indio, se involucrara en el abasto. También se impedía la participación indirecta en la obligación a través de las mujeres, hijos y terceras personas relacionadas con funcionarios indios ${ }^{69}$. La provisión de que no hubiese carnicerías en pueblos de indios se mantuvo durante 15 años; durante este tiempo, en Tlaxcala, el abasto fue proveído por particulares que habían obtenido licencias que convirtieron la venta de carne en un estanco particular. Es verdad que el Cabildo no tuvo participación económica de este rubro, pero también es verdad que por encima de los intereses de obtener beneficios del estanco, se encontraba el interés de los indios principales de Tlaxcala de mantener alejados de sus tierras a los ganados y a los estancieros.

Tal como señala Andrea Martínez Baracs, una constante en la historia colonial tlaxcalteca será la lucha de los estancieros y los comerciantes españoles por conquistar en la provincia mayores espacios económicos, políticos y administrativos ${ }^{70}$. Las élites tlaxcaltecas siempre reaccionaron con temor ante los anuncios de las autoridades españoles con los que veían vulnerada su autonomía, de tal manera que el tema de la defensa de la tierra será una de sus reclamaciones más habituales. Como mejor ejemplo, su reacción a las congregaciones poblacionales anunciada en 1560, que al parecer de los principales de Tlaxcala, generaría que las zonas de tierras de cultivo quedaran deshabitadas y las haría susceptibles de ser mercedadas a españoles ${ }^{71}$. Los indios macehuales, que serían congregados en pueblos, abandonarían su trabajo para las casas señoriales, además, serían convertidos en tributarios para dejar de ser terrazgueros, es decir, dejarían de servir a los señores de Tlaxcala para pechar directamente al rey. Ante esa perspectiva de pérdida de poder político, el cabildo intentó revocar la medida consiguiendo tan sólo su aplazamiento. No se sabe si finalmente estas con-

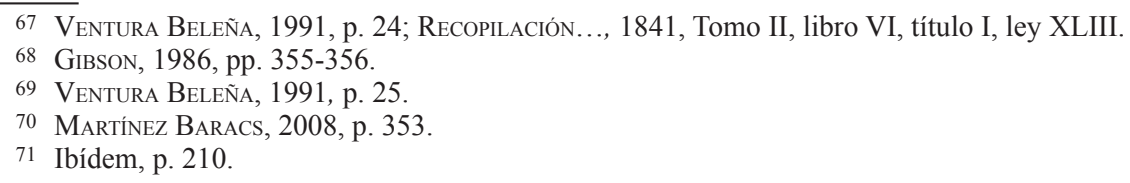

71 Ibídem, p. 210. 
gregaciones tuvieron lugar, pero es de resaltar que en el fondo de todo, se encuentra la lucha contra la penetración de la propiedad rural y la exigencia de mantener a la provincia como un territorio indígena y libre de españoles ${ }^{72}$.

Las peticiones para impedir la venta de carne de vaca en la provincia provinieron siempre del Cabildo indio, sin embargo, se señala en algunas de las ordenanzas expedidas, que las peticiones para revocar el veto también fueron solicitadas por indios. En ello no existe contradicción alguna si pensamos que los intereses de una buena parte de la población, que quizá comenzaba a aficionarse, además de cerdo, a consumir carne de vaca, no fueran los mismos intereses que los de los 'señores de la tierra'. Estos últimos, preocupados por mantener su autonomía política, buscaban a toda costa la autonomía territorial. El potencial daño que tenía el ganado, residía en el nada desdeñable hecho de que serían los animales en busca de pastos, los que se apropiaran de las tierras que hasta entonces seguían constituyendo su patrimonio.

Las disputas constantes del Cabildo con la Real Audiencia por eliminar las estancias de españoles de sus territorios, por otra parte una de las mejor documentadas ${ }^{73}$, nos hablan en este mismo sentido, de la importancia superior que representaba para los principales tlaxcaltecas, mantener alejadas las amenazas a su autonomía territorial. En el mismo sentido que la venta de tierras entre indios y españoles, beneficiaba circunstancialmente a quienes realizaban el trato pero perjudicaba los intereses de la república de indios; la permisión de un sistema de abasto de carnicerías del que era ajena a los beneficios, aunque pudiese beneficiar a los consumidores, podía destruir los serios esfuerzos realizados durante las décadas anteriores en favor de mantener alejado el ganado. Es sabido que una de las causas de pleito más habituales entre españoles e indios en Tlaxcala durante el siglo XVI, fue el que había provocado la introducción del ganado mayor en la provincia. Con ello, la apropiación de las zonas de pastoreo y como hemos visto, el monopolio del sacrificio y la venta de los animales $^{74}$. Los indios, quienes sólo incursionaron en la ganadería menor, no estuvieron interesados tanto en mantener las tierras para las explotaciones de ganadería extensiva, como en que los españoles y sus ganados estuviesen alejados de sus tierras de cultivo. Incluso, en el caso de las ovejas del cabildo de Tlaxcala, en 1593 los rebaños serán vendidos bajo el argumento de que el negocio del ganado les era ajeno ${ }^{75}$. Por otra parte, también encontraremos un gran número de quejas sobre ovejas que invadían las sementeras de los indios ${ }^{76}$.

Como bien señala Chevalier, en la primera mitad de la centuria que nos ocupa, las condiciones geográficas y humanas habían determinado la preponderancia de la ganadería extensiva y favorecieron la ocupación de vastos espacios por los 'señores del ganado', ganaderos españoles en todos los casos. El virrey Mendoza, a sabiendas de que los estancieros establecidos sin permisos ya formaban un grupo con cierto poder económico, se vio en la necesidad de concederles mercedes en nombre del Rey, una vez que la apropiación de la tierra ya había tenido lugar y sabiendo también que

72 Ibídem, pp. 210-217.

73 Martínez Baracs - Assadourian 1991, vol. 6 y 9.

74 Chevalier, 1999, p. 151.

75 Assadourian 1991c, p. 137.

76 Hernández Rodríguez, 1988, vol. 1, 2 y 3. 
los ayuntamientos podían hacerlo por su propia mano y en beneficio de sus propios intereses ${ }^{77}$.

Así, las disposiciones sobre el abasto de la carne, su prohibición, las licencias y las peticiones de los indios tlaxcaltecas por evitar las carnicerías en su provincia, nos estarían hablando de una última fase en los intentos de la república de indios de Tlaxcala por retrasar el avance de los intereses de una naciente élite ganadera en la región, que venía amenazando a los pipiltin tlaxcaltecas, desde hacía por lo menos un par de décadas.

\section{3. 'SEÑORES DE LA TIERRA', 'SEÑORES DEL GANADO' Y LA DISPUTA POR LA TIERRA}

Como se ha señalado, a causa de la intrusión masiva del ganado en sus cultivos, los indios comenzaron a quejarse ante la Audiencia y ante el mismo Felipe II. La disputa por la tierra en la provincia de Tlaxcala se remonta por lo menos a la cuarta década del siglo XVI, cuando el virrey Mendoza otorgó mercedes de tierras a españoles, contraviniendo los privilegios que en Tlaxcala se habían obtenido en $1535^{78}$. Sabemos que hacia la mitad de la centuria, ganaderos no indios comenzaron a establecerse en Tlaxcala y a introducir grandes cantidades de ganado, apacentándolo de manera ilegal o mediante concesiones especiales ${ }^{79}$.

De la multiplicación casi prodigiosa de los ganados, coincidente con esta misma década del siglo XVI, hasta alrededor de $1570^{80}$, resultó el problema de la contención de las vacadas, que constituyeron, como hemos señalado, una verdadera amenaza a los cultivos indios y que propiciaron la puesta en marcha de las segundas Ordenanzas de la Mesta en $1574^{81}$.

Una cédula real expedida en mayo de 1550, mandaba no establecer más estancias en aquellos lugares donde el ganado pudiese causar daños a los cultivos. Ésta anticipaba la solución definitiva que sería puesta en marcha para tratar de contener la expansión del ganado en los territorios centrales y que poblaría el septentrión novohispano en la segunda mitad de la centuria. La orden sugería que "para los dichos ganados se podrían señalar tierras apartadas y yermas donde puedan andar y pacer y no hagan los dichos daños" $"$. Dos meses después y en razón de numerosas peticiones de los indios de Tlaxcala, que recibían perjuicios porque los ganados de las estancias se comían aun los maizales, se ordenará trasladar las estancias ganaderas fuera de los términos de la provincia:

E agora a nos se ha hecho relación, que por la dicha nuestra cedula de suso incorporada, no se remedia el daño, que los yndios naturales della tierra, reciben con las

77 Chevalier, 1999, p. 184.

78 Assadourian, 1991a, p. 124; GibSOn, 1991, pp. 86-87.

79 Gibson, 1991, p. 149.

80 Chevalier, 1999, pp. 179-191.

81 Ventura Beleña, 1991. El texto de dichas ordenanzas está recopilado en pp. 27-63.

82 Puga de, 1985, foja 173. 
dichas estancias: por que dizque que ay muchas en perjuyzio de los dichos indios y los ganados, que en ellas ay les comen sus mayzales y hazen otros daños especialmente en la provincia de Taxcala y que convenia mandarse que dende luego se quitassen las estancias que estavan dentro de los terminos de los pueblos dela dicha provincia de Taxcala y de los otros de las provincias desta tierra y se sacassen los ganados a otras partes donde no hicieren daño a los dichos indios pues avia campos donde los pudiesen poner $^{83}$.

Sin obtener beneficio de esta cédula, los indios de Tlaxcala comenzaron a ver invadidas sus tierras por ganaderos españoles; así, dos años después, el virrey Velasco había llevado el problema a la Audiencia de México y los indios consiguieron que se suprimieran las estancias de ganado mayor, pero el virrey optó por mantener las pastorías de ovejas ${ }^{84}$. Además, desde principios de diciembre hasta mediados de marzo, el ganado vacuno proveniente de otras provincias y estancias tenía permitida la entrada a los pastos tlaxcaltecas a agostar, es decir, a comer los rastrojos que quedaban en las sementeras una vez realizada la cosecha. Esta autorización, pero más aun, su incumplimiento, fue una de las reclamaciones más importantes que hicieron los indios.

El cabildo apeló y el Rey declaró nula la decisión de los oidores. Así, la disputa por las tierras se convirtió en un problema entre los indios de Tlaxcala y el Rey, contra las disposiciones que Don Luis de Velasco ordenaba sin desagraviar por completo a los indios y sin obedecer del todo las disposiciones regias. Tanto el cabildo indio como la corona parecían trabajar en el sentido del retiro total de las estancias y no de minimizar el daño a los indios, sino de eliminarlo. Assadourian señala que durante toda la segunda mitad del siglo XVI, las órdenes virreinales para que los estancieros acataran los períodos de agostadero fueron escasamente respetadas. Para 1574, entre las ordenanzas de la mesta encontraremos que se va a permitir que el ganado que traigan los obligados de las carnicerías pueda pastar a su paso en los baldíos y rastrojos ${ }^{85}$. No sería extraño que estas permisiones agravaran la tensa situación en la provincia con respecto a las intromisiones del ganado y a los establecimientos de venta de carne.

En abril de 1553, Velasco comisionará a Francisco Verdugo, corregidor de Tepeaca, Puebla y después corregidor y Alcalde Mayor en Tlaxcala, para averiguar y hacer justicia en razón de las quejas de los de Tlaxcala contra los ganaderos ${ }^{86}$. Lo anterior, en cumplimiento de una cédula real que ordenaba al virrey que se dirigiera a Tlaxcala personalmente para solucionar el problema de las estancias. Velasco había delegado en el corregidor, quien al final de su visita optó por mantener nueve estancias de ovejas y suprimir otras tres ${ }^{87}$.

El virrey Antonio de Mendoza, en las recomendaciones que heredará Luis de Velasco, se excusará ante su sucesor del daño que recibían los españoles al tener vedado el establecimiento de estancias en los 'tres valles' oaxaqueños, que ya había mandado despejar de ganado en razón de problemas similares a los aquí expuestos. Mendoza

83 Ibídem, f. 173v.

84 Gibson, 1991, p. 87.

85 Ventura Beleña, 1991, pp. 12 y 40.

86 Gerhard, 1992, pp. 209-210.

87 Assadourian, 1991a, pp. 115-119. 
era concluyente al recomendarle que permitirlo, "destruiría a los indios" 88 . Pero, al parecer Velasco, con respecto a Tlaxcala desatendió las recomendaciones de su antecesor.

Las Ordenanzas de la Mesta, inicialmente promulgadas en $1537^{89}$, trataban de responder a los problemas que acarrearon las favorables condiciones de reproducción del ganado menor y mayor sobre todo a los estancieros durante la primera mitad del siglo XVI. En 1574, año en que son renovadas por el virrey Martín Enríquez, el nuevo texto de las Ordenanzas de la Mesta incluirá las Ordenanzas del Agostadero, elaboradas en 1564 por el virrey Luis de Velasco ${ }^{90}$. Este último texto trataba de subsanar las ya habituales disputas entre agricultores y ganaderos por los pastos y de regular su uso mediante la trashumancia. Sin embargo, en razón de la gran cantidad de animales, el movimiento estacional de los rebaños, como se ha visto hasta ahora, fue imposible de controlar de manera adecuada. Las Ordenanzas de la mesta tampoco solucionaron el problema sobre el que Velasco legisló; por el contrario, en previsión de que ya comenzaban a disminuir las cabañas bovinas, habrá más disposiciones en favor de los ganados trashumantes, como la apertura de cañadas y abrevaderos "por aquellas partes y lugares que a los alcaldes de Mesta les pareciese ser necesarias"

La portentosa multiplicación de los rebaños, que en los territorios del centro del virreinato no duraría más que hasta 1565 o 1570, además de problemas para los agricultores, también trajo consigo el 'agotamiento biológico' del territorio donde estos inmensos rebaños se reprodujeron ${ }^{92}$. Chevalier propone que el rendimiento de los rebaños se redujo a mediados del siglo XVI, como consecuencia, en primer lugar, de un nuevo equilibrio entre la vida y los recursos vegetales que había a disposición del ganado mayor. En su opinión, la velocidad de la reproducción de los bovinos, habría disminuido debido a que la capacidad de regeneración de los pastos también habría mermado. En unas décadas el ganado habría agotado las reservas acumuladas durante siglos en praderas completamente vírgenes. En segundo término, el rendimiento de los rebaños habría decaído por la demanda creciente de los comerciantes transoceánicos por los cueros y de los indios por la carne ${ }^{93}$.

Tras este nuevo equilibrio biológico, a partir de la década de 1570, y los problemas sobre invasión de tierras de cultivo, las autoridades novohispanas deberán librar los problemas surgidos en relación a la paulatina disminución de las cabañas, sobre todo, de ganado vacuno.

Según lo que hemos visto, la prohibición de la que hablamos, fue hecha en relación a esta disminución de animales y al daño que hacían los indios matando el ganado de los españoles. Bien en venganza de que los animales estropeaban sus cultivos, bien con el afán de competir ilegalmente en la venta de carne, o más probablemente,

\footnotetext{
88 RuBIO, 1946, p. 71.

89 El texto de las Ordenanzas de 1537 se recoge en el Acta del 14-XI-1542 de las ACCM. El texto señala la confirmación del Rey Carlos I de las Ordenanzas del 31-VII-1537, confirmadas a su vez por el virrey Antonio de Mendoza el 18-IV-1539.

90 Serán elaboradas por el virrey Velasco aunque promulgadas por el marqués de Falces. GARCÍA-ABÁsOLO, 1983, p. 166.

91 Ventura Beleña, 1991, p. 40.

92 Chevalier, 1999, pp. 193-196.

93 Ibídem.
} 
beneficiándose de lo segundo como consecuencia de lo primero. Estas matanzas, sin embargo, no siempre fueron ilegales. En 1560 Mendoza había cercado las estancias para evitar que el ganado saliera e irrumpiera en los cultivos. De tal manera, mientras que los estancieros no acataran la orden, los indios tenían autorización para flechar y matar el ganado que encontrasen pastando en sus cultivos ${ }^{94}$. Para la siguiente década, las ordenanzas ya habían legislado severamente estas permisiones.

Con respecto al retraimiento en la capacidad reproductiva del ganado, además de la inclusión de la cláusula de prohibición de venta de carne en pueblos de indios, en las ordenanzas se legislaba sobre el sacrificio de vacas y terneras. El obligado de la carne, o bien, a quienes se había otorgado licencia para abastecer este producto, estaban impedidos por ordenanza de la Mesta a matar hembras e incluso a movilizarlas junto a los machos ${ }^{95}$. En este mismo sentido, no sólo se prohibirá el sacrificio para consumo de su carne, de vacas y terneras, también se prohibirá a indios, mulatos, negros y mestizos que hubiesen sido vaqueros, poseer lanza y desjarretadera. Esta última, se trataba de una herramienta de uso habitual en las incursiones de rapiña con la que, bien cuatreros o bien compradores de ganado a quienes sólo importaban las pieles, herían al ganado en marcha para después matarlo y desollarlo ${ }^{96}$. La carne de este ganado quedaba a merced de aves y demás animales de rapiña, por lo que la vaca, muerta de esta manera, sólo satisfacía las necesidades de los comerciantes de cueros.

Con respecto a la incursión de los indios en sectores comerciales como la cría en gran escala del ganado, el cultivo de trigo o la apropiación de la manufactura textil, Assadourian señala que los indios de Tlaxcala no tuvieron éxito cuando emprendieron esfuerzos en aquellas ramas del sistema productivo ${ }^{97}$. Gibson por su parte, cree que ni los grandes mercados donde era posible la venta de carne en ciudades de españoles, incentivaron a los indios a la cría de reses $^{98}$. Quizá la cría de ganado mayor no haya sido un emprendimiento comercial por el cual los indios se inclinasen, a pesar de ello, el consumo de carne de res fue habitual y no se contrapuso con lo anterior. A este respecto no queremos dejar de insistir en el hecho de que la complicada experiencia de los indios de Tlaxcala con el ganado bovino, claramente podía haber animado este desinterés.

También vale la pena recordar que las restricciones para que los indios criaran reses fueron severas. En las segundas ordenanzas de la mesta, se prohibió a los naturales poseer ganado mayor y se les impidió que poseyeran caballos propios, aunque po-

94 Miranda, 1944, p. 20.

95 Ventura Beleña, 1991. Cap. 24 y 80 de Ordenanzas de la Mesta.

96 Ibídem. Cap. 44 de Ordenanzas de la Mesta; Argote de Molina, [1582] 1998, pp. 14-15: "En las Indias Occidentales, en las Islas de Santo Domingo, Cuba, Puertorico, Tierrafirme y Nueva España, es notable la multitud de toros y vacas silvestres que la tierra produce y la forma que se tiene en Montear [...] al tiempo que bajan de las Montañas y sierras [las reses] salen contra ellos gentes de a caballo, con Garrochas largas de veynte palmos que en la punta tienen una arma de fierro de hechura de media luna de agudísimos filos que llama Dejarretadera con la cual acometen a las reses al tiempo que van huyendo, y hiriendolas en las corvas de los pies a los primeros botes los dejarretan, y apeandose de los cavallos los acaban acuchillándolos por las rodillas y quitandoles la Piel, de que solamente se aprovechan, dexando la Carne al Monte la cual gastan y consumen en un momento en Tierrafirme unos Perros Silvestres, de que hay grandisimo numero en los Montes de aquellos reynos".

97 Assadourian, 1991b, p. 135.

98 GiBSon, 1986, p. 356. 
dían montar los de sus amos cuando estuvieran trabajando en las estancias. También se ordenó que no se les pagara el jornal en especie, es decir, no podían recibir en pago ganado ni lana. El ganado ovino que se les permitía criar debía permanecer 'orejano', en otras palabras, que no se podía hacer señal alguna en la oreja para establecer su pertenencia ${ }^{99}$. Para los casos en que los indios eran encontrados culpables de matar ganado, generalmente estaban compelidos a pagar los daños al dueño, además de recibir azotes ${ }^{100}$. Las acusaciones venían de los mismos indios que eran puestos como alguaciles por la justicia del cabildo y que tenían su compensación monetaria por cada denuncia que hacían ${ }^{101}$.

\section{CONCLUSIONES}

La administración del negocio de la venta de carne, tal como se colige de algunos datos en actas de cabildo, en un principio fue puesta en manos de las autoridades indias de Tlaxcala. El negocio, al parecer no trajo mayores problemas para el Cabildo sino hasta alrededor de 1550, cuando, a partir de las intrusiones de ganaderos españoles, los bovinos sobre todo, comenzaron a causar estragos en los cultivos. Los indios comenzaron a matar al ganado que amenazaba sus medios de subsistencia y en consecuencia, Martín Enríquez habría ordenado que no hubiese carnicerías en dichos pueblos. El ganado sacrificado por los indios, que probablemente estaba a su cargo para ser cuidado y pastoreado, más probablemente se trataría del ganado que se introducía en sus sementeras. De tal manera que las matanzas pudieron corresponder a una venganza de los indios al no ser escuchadas sus quejas sobre la invasión de estos animales en sus cultivos ${ }^{102}$. El virrey arrebató al cabildo indio la administración del sacrificio del ganado y la venta de su carne, en palabras de Gibson, en razón de que las autoridades indias se habrían puesto del lado de los afectados en la cuestión de la intrusión del ganado en las sementeras. Así, ante la suprema autoridad virreinal, el gobierno indio demostraba no estar capacitado para hacerse cargo de castigar y evitar el sacrificio ilegal ${ }^{103}$.

Discutiendo la idea de que la prohibición de venta de carne en pueblos de indios, buscaba evitar que el negocio recayera en los indios principales de esta provincia, insistimos en el hecho de que la prohibición, las subsecuentes licencias que la revocaban temporalmente y la insistencia del Cabildo indio por restablecerla, estarían más relacionadas con mantener alejada la amenaza del ganado. Por otra parte y ya que este veto tuvo diversas caras, también señalamos el hecho de que en períodos de escasez como el que las autoridades virreinales vislumbraron a partir de que los rebaños ya no se reproducían como antes, la carne era un bien alimentario a cuyo acceso tenían preferencia, en principio, los españoles y en segundo lugar, los nobles indígenas en razón de su extracción social y de sus obligaciones defensivas con la ciudad.

\footnotetext{
99 Ventura Beleña, 1991. Capítulos 64, 56, 76 y 77 de Ordenanzas de la Mesta.

100 Ibídem, p. 21.

101 Ibídem. Capítulo 52 de Ordenanzas de la Mesta.

102 Ibídem.

103 Gibson, 1991, p. 150.
} 
Es bien conocido el sempiterno conflicto entre ganaderos y agricultores, las razones, desde muy antiguo, serán similares a las aquí expuestas: la irrupción del ganado en los cultivos de los labradores y la falta de voluntad por parte de los criadores de respetar los ordenamientos, que, cuando los hubo, intentaron regular las intrusiones estableciendo regímenes de pastos y temporalidades para el acceso del ganado a ellos. La disputa entre los señores del ganado y los señores de la tierra en la provincia de Tlaxcala, tuvo lugar en una coyuntura donde la reproducción de los ganados superó tanto las expectativas biológicas hasta entonces conocidas, como todos los esfuerzos que se hicieron por contener los rebaños. Por una parte, coincidió con la máxima capacidad reproductiva del ganado en condiciones de pastoreo extensivo que se ha visto nunca, y por otra, con un momento de frágil equilibrio entre los poderes políticos indio y español.

Las peticiones del cabildo indio de Tlaxcala por mantener fuera de sus sementeras a los rebaños y por mantener a su ciudad libre de los comerciantes de la carne, perfilaron una disputa que superó los intereses comerciales por mantener los beneficios del estanco de las carnicerías. Fue la presencia de las vacadas a que los pastos de la región alimentaron, la que en última instancia, sostuvo el conflicto por la tierra y por mantener la autonomía política del territorio.

\section{REFERENCIAS BIBLIOGRÁFICAS}

ACTAS

1859 Actas de Cabildo de la Ciudad de México. Edición de Ignacio Bejarano. México. Edición del Municipio Libre, Libro III.

ACTAS

1889 Actas de Cabildo de la Ciudad de México. Edición de Ignacio Bejarano. México. Edición del Municipio Libre, Libros I y II.

Argote de Molina, Gonzalo

1998 Libro de la montería que mando escrevir el muy alto y muy poderoso Rey Don Alfonso XI Alonso de Castilla, y de Leon, ultimo deste nombre. Acrecentado por Gonzalo Argote de Molina [1582]. Toledo. Antonio Pareja Editor.

Assadourian, Carlos Sempat

1991a "La lucha de los señores de Tlaxcala contra las estancias españolas y el agostadero".

En Tlaxcala, una historia compartida. México. CONACULTA - Gobierno de Tlaxcala, vol. 9, pp. 115-127.

1991b "La reorganización política y el cabildo". En Tlaxcala, una historia compartida. México. CONACULTA - Gobierno de Tlaxcala, vol. 9, pp. 53-65.

1991c "Tlaxcala en la nueva economía". En Tlaxcala, una historia compartida. México. CONACULTA - Gobierno de Tlaxcala, vol. 9, pp. 130-137.

Castillo Palma, Norma Angélica

2001 Cholula, sociedad mestiza en ciudad india. Un análisis de las consecuencias demográficas, económicas y sociales del mestizaje en una ciudad novohispana (1649-1796). México. UAM Iztapalapa - Plaza y Valdés. 
Celestino, Eustaquio; Valencia, Armando y Medina Constantino

1985 Actas de Cabildo de Tlaxcala 1547-1567. México. AGN - Instituto Tlaxcalteca de Cultura - CIESAS.

Chevalier, François

1999 La formación de los latifundios en México, tierra y sociedad en los siglos XVI y XVII.

Trad. del francés de Antonio Alatorre. México. Fondo de Cultura Económica.

Domínguez Ortiz, Antonio

1973 Las clases privilegiadas en el antiguo régimen. Madrid. Istmo.

1992 Historia de Sevilla. Salamanca. Publicaciones de la Universidad de Sevilla.

DusSENBERry, William $\mathrm{H}$.

1948 "The regulation of meat supply in sixteenth Century Mexico City". The Hispanic

American Historical Review. Carolina del Norte, vol. XXVIII, parte 1, pp. 38-52.

García-ABÁsolo, Antonio F.

1983 Martín Enríquez y la reforma de 1568. Sección Historia. Serie V Centenario del

Descubrimiento de América, núm.2. Sevilla. Excma. Diputación de Sevilla.

Gerhard, Peter

1992 Síntesis e índice de los mandamientos virreinales 1548-1553. México. Instituto de Investigaciones Históricas - UNAM.

GiBson, Charles

1986 Los aztecas bajo el dominio español, 1519-1810. México. Siglo XXI.

1991 Tlaxcala en el siglo XVI. México. Fondo de Cultura Económica.

GonzÁlez, María del Refugio

1985 "Estudio introductorio". En Cedulario de la Nueva España de Vasco de Puga, Ed.

Facsimilar. México. Centro de Estudios de Historia de México CONDUMEX, pp.

XIX-LVIII.

HERNÁNDEZ IÑIGO, Pilar

2006 "Abastecimiento y comercialización de la carne en Córdoba a fines de la Edad

Media". Meridies. Córdoba, vol. VIII, pp. 73-120.

HERNÁNDEZ Rodríguez, Rosaura

1988 Catálogo de documentos del siglo XVI del Archivo General de Tlaxcala. México.

Gobierno del Estado de Tlaxcala - Archivo General de la Nación, 3 vols.

Martínez Baracs, Andrea

2008 Un gobierno de indios: Tlaxcala, 1519-1750. México. Fondo de Cultura Económica

- CIESAS - Colegio de Historia de Tlaxcala.

Martínez Baracs, Andrea - Assadourian, Carlos Sempat (comp.)

1991 Tlaxcala, una historia compartida. México. CONACULTA - Gobierno de Tlaxcala, vol. 6 y 9.

Matesanz, José

1965 "Introducción a la ganadería en Nueva España, 1521-1535". Historia Mexicana.

México, vol. XIV, núm. 55-56, pp. 533-566.

Miranda, José

1944 "Notas sobre la introducción de la mesta en la Nueva España". Revista de Historia de América. México, nº 17, pp. 1-24.

Monsalvo Antón, José María

1988 El sistema político concejil, el ejemplo del señorío medieval de Alba de Tormes y su concejo de villa y tierra. Salamanca. Ediciones de la Universidad de Salamanca. 
MotTA, J. Arturo

2006 “Tras la heteroidentificación. El 'movimiento negro’ costachiquense y la selección de marbetes étnicos”. Dimensión Antropológica. México, año 13, vol. 38.

Puga, Vasco de

1985 Cedulario de la Nueva España [1563]. Ed. Facsimilar. México. Centro de Estudios de Historia de México - CONDUMEX.

Quiroz, Enriqueta

2003 «Del estanco a la libertad: el sistema de la venta de carne en la ciudad de México (1700 - 1812)». En del VALLE PAVÓN (coord.): Mercaderes, comercio y consulados de Nueva España en el siglo XVIII. México. Instituto Mora, pp. 191-223.

RECOPILACIÓN

1841 Recopilación de Leyes de los Reinos de Indias mandadas imprimir y publicar por la Magestad Católica del Rey Don Carlos II [1680]. Madrid. Boix editor. Tomo II.

RuBio MaÑé, Ignacio

1946 Don Luis de Velasco, el virrey popular. México. Ediciones Xochitl.

TORQuemadA, Fray Juan de

1975 Monarquía Indiana [1615]. Ed. Facsimilar. México. Porrúa, tomo III.

Tudela de la Orden, José

1993 Historia de la ganadería hispanoamericana. Madrid. Agencia Española de Cooperación Internacional.

Ventura Beleña, Eusebio

1991 Recopilación Sumaria de todos los autos acordados de la Real Audiencia y Sala del Crimen de esta Nueva España y provincias de su superior gobierno [1787]. Estudio introductorio de María del Refugio González. México. UNAM - Instituto de Investigaciones Jurídicas. 